\title{
DESARROLLO DE LOS VERTICILOS SEXUALES DE VANROYENELLA PLUMOSA NOVELO \& PHILBRICK (PODOSTEMACEAE)
}

\author{
Guillermina Murguía SÁnchez \\ Facultad de Ciencias \\ Universidad Nacional Autónoma de México \\ Apdo. postal 70-356, 04510 México, D.F. \\ Alejandro Novelo R. \\ Instituto de Biología \\ Universidad Nacional Autónoma de México \\ Apdo. postal 70-233, 04510 México, D.F. \\ C. Thomas PhiLBRICK \\ Department of Biological and Environmental Sciences \\ Western Connecticut State University \\ Danbury, CT 06810, USA \\ Y \\ G. Judith MÁrquez Guzmán \\ Facultad de Ciencias \\ Universidad Nacional Autónoma de México \\ Apdo. postal 70-356, 04510 México, D.F.
}

\section{RESUMEN}

El cuerpo vegetativo de Vanroyenella plumosa Novelo \& Philbrick (subfamilia Podostemoideae) posee raíz, hojas y un tallo taloide dorsiventralmente aplanado que, durante la etapa reproductora, desarrolla cavidades ocupadas por fascículos florales. En este trabajo se estudió la embriología de esta especie y se relacionó el desarrollo floral con la posición de las flores en el cuerpo vegetativo de la planta, la posición de la planta sobre la roca y de la planta con el nivel del agua. Vanroyenella plumosa presenta dos estambres cuyas anteras son tetrasporangiadas, con un desarrollo de la pared de tipo Básico, tétradas tetraédricas y polen bicelular. El gineceo es bicarpelar y bilocular con placentación axial y presenta dos estigmas con idioblastos cuya vacuola contiene proteínas y carbohidratos. Los óvulos son anátropos, bitégmicos y tenuinucelados. El saco embrionario es monospórico y tetracelular, del tipo Apinagia. En Vanroyenella el desarrollo floral ocurre en el interior del tallo mientras la planta está sumergida, allí se forman los gametos en etapas muy tempranas. Cuando el nivel del agua baja, los pedicelos se alargan y sobreviene la antesis, en el ambiente aéreo. 
La pared del ovario sostiene el desarrollo de las semillas una vez que el resto del tejido vegetativo ha muerto.

Palabras clave: androceo, gineceo, plasmodio nucelar, saco embrionario, Vanroyenella, Podostemaceae, México.

\begin{abstract}
The vegetative body of Vanroyenella plumosa Novelo \& Philbrick (subfamily Podostemoideae) is composed of roots, leaves and a dorsiventrally flattened thalloid stem which, in the reproductive stage of the life cycle, develops cavities containing fascicles of flowers. In this work the embryology of this species was studied. Floral development depends on the flower position in the vegetative body of the plant, the plant position on the rock and the water level in the river. Vanroyenella plumosa possesses two stamens with tetrasporangiate anthers; the anther wall formation is of the basic type. Tetrads are tetrahedral, and the pollen is bicellular. The gynoecium is bicarpelar and bilocular with axial placentation and has two stigmas with idioblasts whose vacuoles contain proteins and carbohydrates. The ovules are anatropous, bitegmic and tenuinucellate. The embryo sac is monosporic in its origin and tetracellular of the Apinagia type. In Vanroyenella floral development occurs in the interior of the stem while the plant is submerged, and it is during this very early stage that the male and female gametes are formed. When the water level recedes, the pedicels elongate and anthesis occurs above water. The ovary wall supports the seed development after the rest of the vegetative tissue has died.
\end{abstract}

Key words: androecium, gynoecium, nucellar plasmodium, embryo sac, Vanroyenella, Podostemaceae, Mexico.

\title{
INTRODUCCIÓN
}

La familia Podostemaceae es la más grande de las angiospermas acuáticas estrictas, con 270 especies (Cook, 1996; Philbrick y Novelo, 1998) que se agrupan en tres subfamilias: Tristichoideae, con 5 géneros, Podostemoideae, con 44 géneros (Jäger-Zürn, 1997) y Weddellinoideae con un género (Kita y Kato, 2001) respectivamente. Se distribuye principalmente en las regiones tropicales y subtropicales del mundo (Philbrick y Novelo, 1995) y puede ser indicadora de ríos y arroyos limpios (O’Neill et al., 1997).

Las adaptaciones morfológicas de las podostemáceas al ambiente acuático han resultado en una organización nada ortodoxa que diversos autores han descrito como "parecida a algas", "parecida a líquenes", "parecida a musgos", etc. (Graham y Wood, 1975; Cronquist, 1981; van Steenis, 1981). La morfología de las Podostemaceae varía enormemente $y$, con frecuencia, muestra un cuerpo vegetativo taloide debido a que se han comprimido dorsiventralmente las raíces, los tallos o ambos. Las hojas pueden tener formas variadas y tamaños de hasta $2 \mathrm{~m}$ de largo en el género Mourera, o bien estar reducidas a pequeñas escamas de una sola capa de células que las hacen parecer un musgo, como en el género Tristicha. En cuanto a otros caracteres, como el número de estambres y tépalos por flor, costillas en las cápsulas, etc., hay un considerable polimorfismo a distintos niveles taxonómicos y aún entre individuos (Rutishauser, 1997).

Estas hierbas crecen sumergidas en ríos con corrientes rápidas y en cascadas, donde permanecen adheridas firmemente a substratos rocosos (Graham y Wood, 1975; 
Philbrick, 1984) por la acción de los pelos unicelulares que se desarrollan en la parte ventral del tallo taloide (Rutishauser, 1997), cuyas paredes celulares, ricas en substancias pécticas, interactúan con una capa de cianobacterias limosas que, como "biopelícula" con propiedades viscoelásticas, constituye una potente goma adhesiva (Jäger-Zürn, 2000).

En el ciclo sexual de las podostemáceas, las flores son hermafroditas, comúnmente solitarias o rara vez en fascículos (van Royen, 1953) y la antesis es aérea (Philbrick y Novelo, 1993). La fase gametofítica se inicia mientras el cuerpo vegetativo se encuentra sumergido, pues las flores se forman dentro de la planta (Schnell, 1967).

Vanroyenella es un género monotípico de la familia Podostemaceae y endémico de México (Novelo y Philbrick, 1993). Se encuentra en el límite norte de la distribución de la familia Podostemaceae en el Continente Americano y probablemente está relacionado estrechamente con Marathrum (Rutishauser et al. 1999; Kita y Kato, 2001). Vanroyenella plumosa Novelo \& Philbrick, se conoce solamente de dos localidades, una en Jalisco (Fig. 1) y otra en Oaxaca (Fig. 2), donde el lecho rocoso es granítico.

Vanroyenella plumosa crece únicamente en zonas muy soleadas del río; la floración se inicia al final de la estación lluviosa (fines de noviembre) y se extiende hasta fines de marzo (Novelo y Philbrick, 1993). Para estas fechas el caudal del agua ha disminuido notablemente. El cuerpo vegetativo crece sobre las rocas desde profundidades de $20 \mathrm{~cm}$ hasta la superficie (Figs. 2, 3). En ese intervalo, se observan distintas etapas del desarrollo: en el fondo sólo es visible el cuerpo vegetativo, a unos pocos centímetros bajo la superficie del agua se encuentran las fascículos de la planta (Fig. 4) y, en el límite del agua (parte aérea), sobresalen los pedicelos florales exponiendo las flores en antesis y los frutos en desarrollo (Fig. 5).

En el cuerpo vegetativo de $V$. plumosa se distinguen la raíz y el tallo taloide dorsiventralmente aplanado; en éste, las hojas nuevas emergen de cavidades en la base de las hojas jóvenes pero, en la etapa reproductora, tales cavidades son ocupadas por fascículos en desarrollo (Rutishauser et al., 1999). Cada fascículo está formado por 4 a 10 flores que surgen en secuencia, lo que da a la estructura reproductiva una apariencia piramidal escaleriforme (Novelo y Philbrick, 1993). Las flores son hermafroditas, zigomórficas y envueltas en una delgada espatela clavada. Cada flor presenta 3 tépalos libres con ápice subulado o a veces bifurcado, dos estambres libres y alternos con los tépalos, confinados en un lado de la flor y un gineceo cuyo ovario prominente presenta dos estructuras apicales que han sido consideradas como estilos (Novelo y Philbrick, 1993), estilodios (Jäger-Zürn, 1997) o estigmas (Rutishauser et al., 1999) (Fig. 6).

En este trabajo se estudió la embriología de Vanroyenella plumosa, hasta la etapa de antesis, con dos objetivos: 1) comparar los resultados con los descritos para otros miembros de la familia Podostemaceae y 2) conocer la relación que existe entre las distintas etapas del desarrollo floral con: a) su posición en el cuerpo vegetativo de la planta y b) la posición de la planta sobre la roca y la posición de la planta con respecto al nivel del agua.

\section{METODOLOGÍA}

En 1995 y 1997, durante la época de secas, se colectaron fascículos de Vanroyenella plumosa en diferentes etapas de desarrollo (desde primordios florales, hasta flores en 

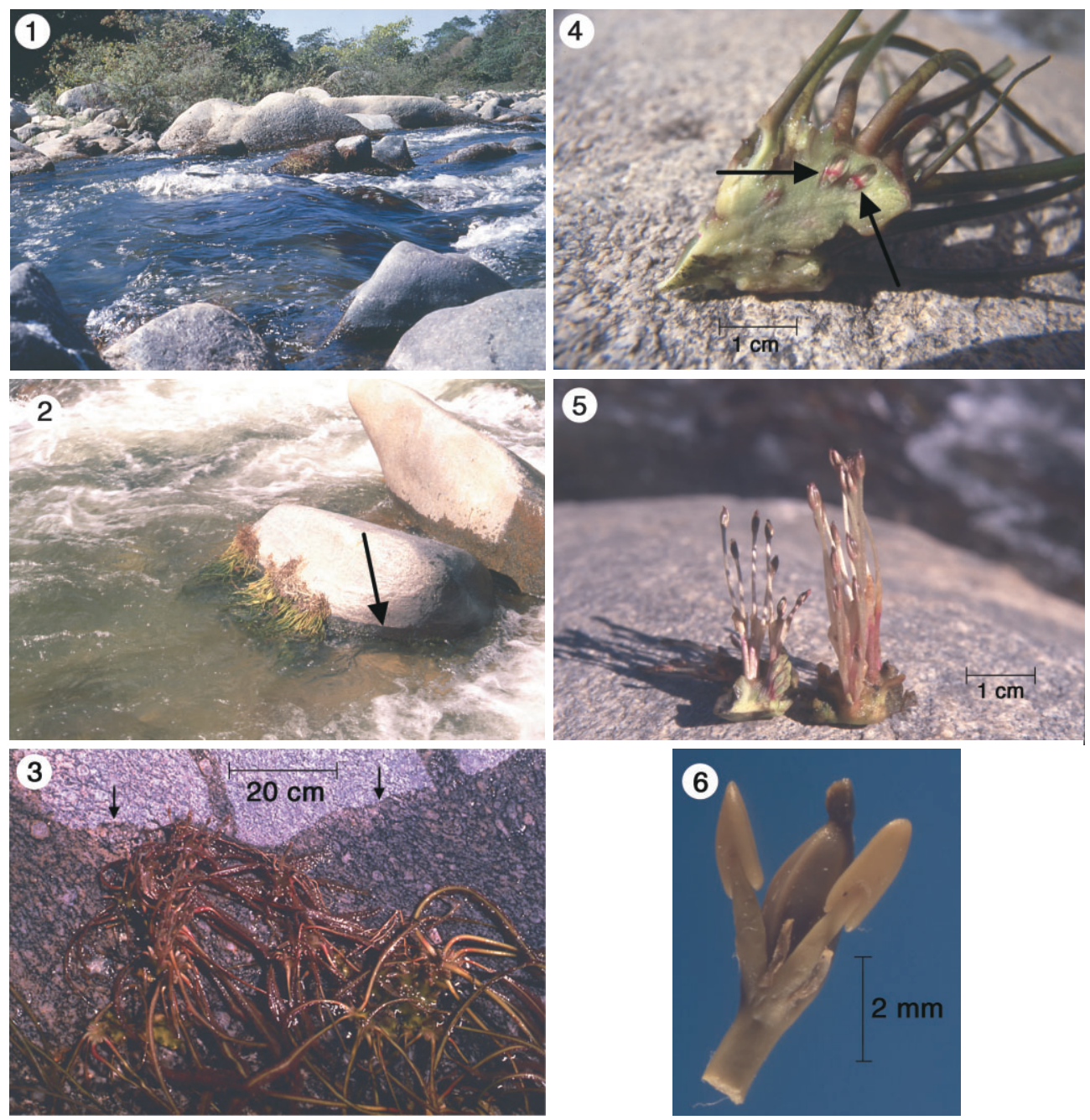

Fig. 1. Vista general del río Horcones, Jalisco, con grandes rocas y fuerte corriente. Fig. 2. Vista de una roca con Vanroyenella plumosa en el Río Casquito, Oaxaca. Las flores fasciculadas y los frutos están ubicados por arriba del nivel del agua, señalado por la flecha. Fig. 3. Acercamiento de una roca con plantas de $V$. plumosa ligeramente por arriba del nivel del agua (las flechas señalan el límite de la zona húmeda). Fig. 4. Las flores fasciculadas están inmersas en la parte inferior del tallo aplanado, etapas I (izquierda) y II (derecha) del desarrollo. Fig. 5. Fascículos de las etapas III a V del desarrollo emergiendo del tallo aplanado (izquierda), frutos en desarrollo (derecha). Fig. 6. Flor de la etapa IV del desarrollo. Se han retirado la espatela y una parte del pedicelo para exponer los tépalos alternos con los estambres y el gineceo. 
antesis) provenientes de las dos localidades donde se conoce esta especie (Novelo y Philbrick, 1997): Río Horcones, Jalisco (marzo 1995 y 1997), Río Casquito, Oaxaca (noviembre 1995 y 1996). En cada localidad se colectaron muestras de ocho plantas (de rocas separadas) durante dos estaciones de floración para cada población (32 plantas en total). El material se colectó siguiendo transectos de 0 a $5 \mathrm{~cm}$ y 5 a $10 \mathrm{~cm}$ por debajo del agua. Los ejemplares de herbario correspondientes están depositados en el Herbario Nacional de México (MEXU).

Para esta investigación se estudiaron las muestras del transecto 0 a $5 \mathrm{~cm}$ de profundidad, ya que en este intervalo los fascículos florales pudieron dividirse en grupos que representan las siguientes etapas de desarrollo: (I) fascículos tempranos inmersos en la región basal expandida del tallo postrado, no visibles sobre su superficie (Fig. 4); (II) fascículos visibles sólo como una protuberancia sobre la superficie del tallo postrado; (III) fascículos emergiendo menos de $5 \mathrm{~mm}$ en el tallo postrado; (IV) fascículos emergiendo más de $5 \mathrm{~mm}$ sobre el tallo postrado; (V) fascículos en antesis, sobre pedicelos alargados (Fig. $5)$.

Las muestras fueron fijadas en el campo usando dos soluciones fijadoras: a) F.A.A. (formaldehído, alcohol etílico de 96ํa ácido acético glacial y agua, en una proporción de 5:50:10:35) a temperatura ambiente y b) 5\% glutaraldehído + 4\% paraformaldehído en buffer de s-collidina $(0.1 \mathrm{~mol} / \mathrm{L}, \mathrm{pH} 7.2)$ a $\sim 4 \stackrel{\circ}{\mathrm{C}}$ por 24 horas.

Cada fascículo se separó longitudinalmente, formándose dos mitades iguales de botones florales. Una mitad del fascículo fue deshidratada en una serie gradual de alcohol etílico e incluida en Paraplast (p.f. 57-60 ํㅡ) (Johansen, 1940). La otra mitad se deshidrató en una serie gradual de acetona y fue incluida en la resina sintética JB-4. Con el material incluido en Paraplast, se utilizó un microtomo rotatorio para obtener secciones de $8 \mu \mathrm{m}$ de grosor. Estas secciones fueron teñidas con safranina-verde rápido para describir del desarrollo floral o fueron usadas para detectar la presencia de almidón, lípidos, polisacáridos insolubles y proteínas mediante la aplicación de los siguientes reactivos: lugol, rojo ' $O$ ' de aceite, ácido peryódico-reactivo de Schiff y azul negro de naftol, respectivamente. Con el material incluido en JB-4, se utilizó un ultramicrotomo (navaja de vidrio) para obtener cortes de 2-3 $\mu \mathrm{m}$ de grosor. Éstos fueron teñidos con azul de toluidina y se utilizaron para obtener microfotografías mediante un fotomicroscopio Zeiss.

Para observar tétradas en anteras jóvenes se aplicó una gota de acetocarmín a 1\% y se calentó ligeramente la muestra, posteriormente se aplicó una gota de solución Hoyer's, se realizó squash y se tomó la fotografía. Se utilizó microscopía electrónica de barrido (MEB) para la observación de estigmas de flores maduras de la etapa (IV), estos fijados en F.A.A. y deshidratados en una serie de alcoholes graduales hasta alcohol absoluto, pasados a punto crítico y luego cubiertos con oro.

\section{RESULTADOS}

Fascículo

Las fascículos tienen 2 a 5 pares florales que surgen secuencialmente dentro de cada cavidad. Como es típico para la subfamilia Podostemoideae, cada flor está cubierta por una espatela en forma de saco. En las etapas (I) y (II) del desarrollo de las fascículos 
tiene lugar la formación del androceo y del gineceo (Fig. 4). En las etapas (III) - (V) solamente hay un incremento en volumen y longitud de las estructuras reproductoras y se realiza la síntesis de distintos metabolitos. En la etapa (V) ocurre el alargamiento rápido del pedicelo, liberando a la flor de la espatela; en la antesis, los órganos reproductores quedan expuestos al ambiente aéreo (Figs. 5, 6).

\section{Desarrollo de la pared de la antera}

En los botones florales de fascículos de la etapa (I) se observa el desarrollo de la pared de la antera y la transformación del tejido esporógeno en células madres del polen. El primordio de antera está formado por células parenquimáticas rodeadas por la protodermis que dará origen a la epidermis. En los ángulos de este primordio se diferencian células arquesporiales que se dividen periclinalmente, formando dos capas: una capa parietal primaria en posición hipodérmica y una capa más interna que dará origen al tejido esporógeno. A su vez la capa parietal primaria se divide periclinalmente, originando la capa parietal secundaria externa, adyacente a la epidermis y la capa parietal secundaria interna, que rodea al tejido esporógeno.

La capa parietal secundaria interna se divide periclinalmente y forma una capa media interna y el tapete (Fig. 7); después, la capa parietal secundaria externa se divide periclinalmente formando el endotecio y una capa media externa. Una u otra de las capas medias puede experimentar otra división periclinal. Así, la pared de la antera queda formada por: la epidermis, el endotecio, dos a tres capas medias y el tapete (Fig. 8). Este desarrollo de la pared de la antera es del tipo Básico (Davis, 1966).

En los botones más grandes de fascículos de la etapa (I), cuando en los lóculos de la antera las células madres de las microsporas están a punto de entrar en meiosis, la pared de la antera está constituida por epidermis, endotecio y tapete monoestratificado del tipo secretor, con células mononucleadas u ocasionalmente binucleadas. Las capas medias ya han sido consumidas.

En fascículos de la etapa (II) del desarrollo, la pared de la antera conserva solamente la epidermis y el endotecio. En los botones más pequeños de esta etapa, las células epidérmicas contienen granos de almidón, al igual que las del endotecio, y han depositado una cutícula en la pared celular externa.

En las etapas (III) - (V) del desarrollo las células del endotecio han incrementado su tamaño y presentan, en el interior de las paredes celulares tangenciales, engrosamientos en forma de espiral. En tales etapas, el endotecio circunda a los sacos polínicos, incluso en la región del tejido conectivo; en éste las células contienen granos de almidón. Las dos anteras de cada flor son tetrasporangiadas y difieren morfológicamente entre sí. Secciones transversales (Fig. 9) muestran una distancia diferente entre las tecas de cada antera. En ambas la dehiscencia es introrsa.

\section{Microsporogénesis y microgametogénesis}

En fascículos de la etapa (I) las anteras de los botones más grandes contienen células madres de las microsporas, envueltas por una pared de calosa. En los botones florales más 
pequeños de la etapa (II) las anteras producen tétradas tetraédricas como resultado de la meiosis (Fig. 10). En esta fase, cuando la pared de calosa desaparece, las microsporas unicelulares se liberan en el lóculo. En los botones florales más grandes, las células del tapete se desintegran y restos de sus contenidos se adhieren a la pared de los granos de polen. Cada grano de polen tiene dos células, una vegetativa y otra generatriz (Fig. 11). Los granos de polen contienen carbohidratos, lípidos y proteínas. Al momento de la antesis (etapa V) los granos de polen son bicelulares y se diseminan en mónadas.

Desarrollo del gineceo

\section{a) Estigma}

En la etapa más temprana del desarrollo de las fascículos florales (etapa I), los dos estigmas en cada botón floral están delimitados por una epidermis monoestratificada adyacente al tejido parenquimático; en la hipodermis se forman idioblastos cuyo citoplasma contiene un núcleo prominente y una vacuola que aumenta de volumen. Este incremento continúa en la etapa (II). En las etapas (III) - (V) la vacuola, que ocupa la mayor parte del citoplasma en el idioblasto, contiene carbohidratos e inclusiones protéicas. La epidermis estigmática posee una cutícula que presenta reacción positiva a lípidos y el citoplasma contiene carbohidratos. El tejido de transmisión, que se extiende desde los estigmas hasta la parte superior de la placenta masiva, presenta células alargadas con citoplasma denso, acumulaciones de naturaleza lipídica y carbohidratos (Fig. 12). En la madurez, los dos estigmas son cónicos pero el ápice es 2- ó 3-furcado y en la superficie estigmática se proyectan los voluminosos idioblastos hipodérmicos como estructuras convexas (Fig. 13). Sin embargo, Rutishauser et al. (1999) afirman que en V. plumosa, la mayoría de las flores tiene lóbulos estigmáticos enteros.

\section{b) Pared del ovario}

Durante el desarrollo floral la pared del ovario está formada por 4 a 6 capas celulares que incluyen la epidermis externa e interna monoestratificadas y entre ambas un parénquima. En las etapas (I) y (II) del desarrollo del fascículo los cambios más significativos son de naturaleza química y corresponden al contenido de substancias presentes en estas células y al incremento en volumen del tejido.

En fascículos de la etapa (I) las células de la pared del ovario en los botones florales más pequeños no presentan substancias de reserva (Fig. 14). El almidón y los lípidos aparecen primero en los botones florales mayores de la misma etapa (I) y se depositan secuencialmente desde la base hacia el ápice del gineceo. En la etapa (II) las células de la epidermis interna de la pared del ovario empiezan a acumular inclusiones lipídicas esféricas; al mismo tiempo se deposita una cutícula bastante más gruesa que la que se desarrolla sobre las células epidérmicas externas (Fig. 15).

A partir de la etapa (III), en las células de la epidermis interna de la pared del ovario, las gotitas de lípidos coalecen y ocupan el volumen total; en este momento la cutícula está 

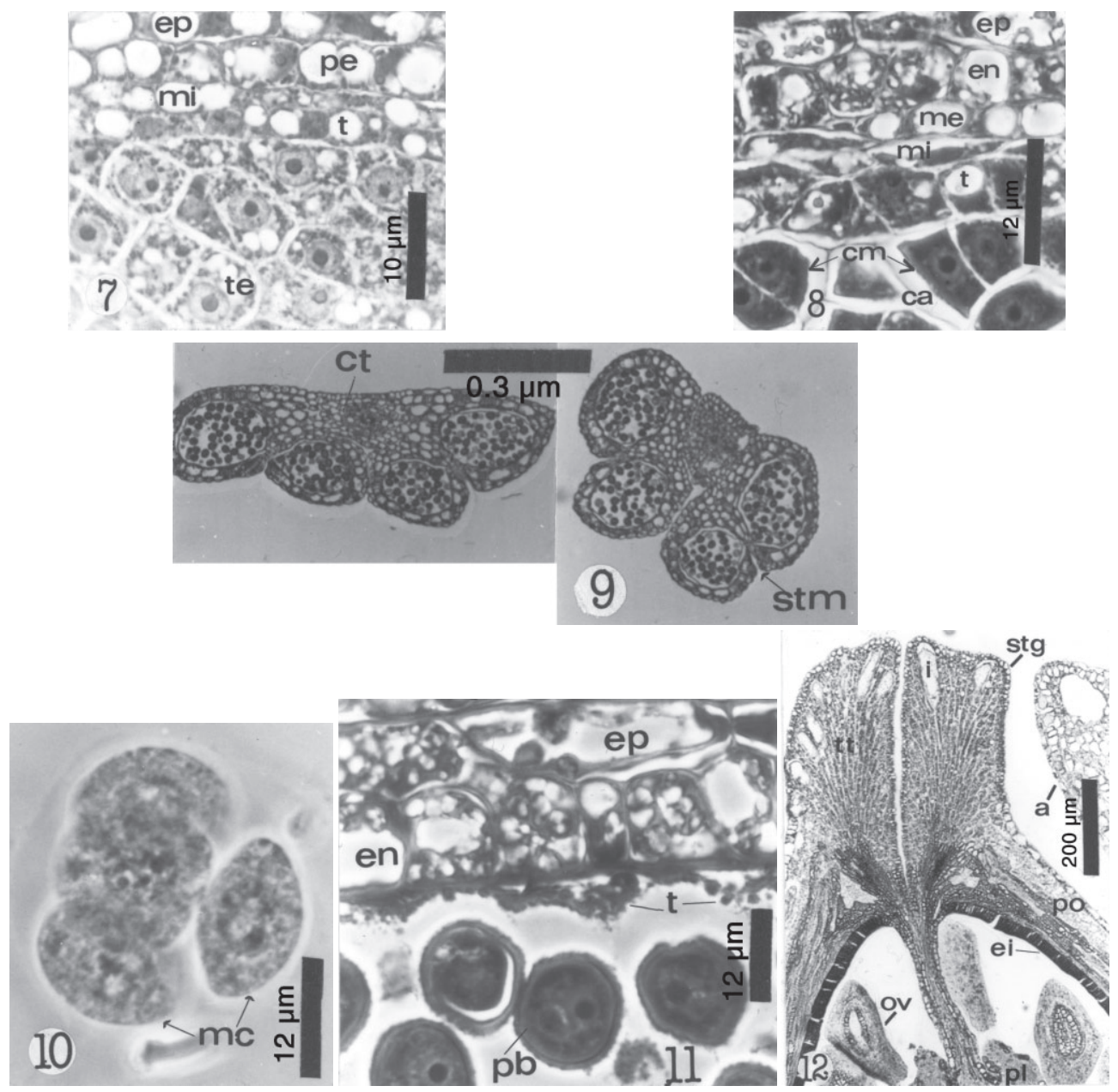

Figs. 7-11. Desarrollo del microsporangio y del microgametofito. Fig. 7. Botones pequeños de la etapa (I). La división de la capa parietal secundaria interna origina una capa media interna (mi) y el tapete (t). Epidermis (ep), capa parietal secundaria externa (pe), tejido esporógeno (te). Fig. 8. Botones grandes de la etapa (I). Pared de la antera del tipo Básico de desarrollo. Epidermis (ep), endotecio (en), capa media externa (me), capa media interna (mi) y tapete (t); este último delimita a las células madres de las microsporas (cm), que presentan depósito de calosa (ca). Fig. 9. Botones grandes de la etapa (III). Corte transversal de anteras maduras, se observa la desigualdad de sus formas. Tejido conectivo (ct), estomio (stm). Fig. 10. Tétrada tetraédrica de microsporas (mc). Fig. 11. Botones de la etapa (II). Granos de polen bicelular (pb). Epidermis (ep) y endotecio (en) con gránulos de almidón en el citoplasma; restos del tapete (t). Fig. 12. Gineceo de la etapa (IV). Estigmas maduros (stg) con idioblastos (i) y tejido de transmisión (tt). Ovario bilocular y placenta axial (pl), pared del ovario (po) con epidermis interna lipídica (ei), óvulos (ov). Antera (a). 
muy engrosada. Las dos capas de células parenquimáticas próximas a la epidermis interna del ovario también contienen lípidos, además del almidón (Fig. 16). Una vez madura, la pared del ovario presenta dos regiones estructuralmente diferentes: las zonas costal e intercostal. La zona costal contiene haces vasculares, rodeados por fibras, que corren longitudinalmente por el parénquima, mientras que la intercostal carece de tales haces. Se detectaron grandes cantidades de almidón en las células parenquimáticas de ambas zonas. En corte transversal del ovario, se observan seis regiones costales, tres por cada uno de los carpelos. Estas zonas conforman las costillas prominentes que se observan en las valvas de la cápsula madura.

Óvulo, megagametofito y plasmodio nucelar

En fascículos de la etapa (I) los botones florales más pequeños muestran el crecimiento y la curvatura inicial de la nucela. En los botones más grandes, la nucela ha completado su curvatura y presenta en el extremo micropilar a la célula arquesporial. En la etapa (II) se forman los tegumentos, el plasmodio nucelar y el saco embrionario. En los botones florales más pequeños de esta fase se adquiere la forma característica de óvulo anátropo y el tegumento externo se desarrolla más rápidamente que el tegumento interno. Mientras ocurre la meiosis en la célula madre de la megaspora, se inicia la degradación de las paredes celulares de la nucela (Fig. 17), excepto en el extremo micropilar y de esta manera se forma un plasmodio nucelar.

La célula arquesporial se diferencia directamente en célula madre de la megaspora, en posición subepidérmica. En los botones más grandes de la etapa (II), la meiosis-I en la célula madre de la megaspora es seguida por la citocinesis y únicamente la diada calazal completa la meiosis-II, produciéndose dos núcleos haploides; de éstos, el núcleo del extremo micropilar de la diada calazal es el que origina, por dos procesos mitóticos, un saco embrionario monospórico y tetracelular del tipo Apinagia (sensu Nagendran, 1974; Battaglia, 1987); externamente a éste persiste la diada micropilar, que es de apariencia picnótica (Fig. 17) con forma de "luna creciente", como se observa en otras Podostemaceae. A partir de la etapa (III) los tegumentos muestran un considerable aumento en longitud. El tegumento externo, de 4 a 5 estratos celulares, contiene almidón abundante y forma el micrópilo, mientras que el tegumento interno, con dos capas celulares de grosor, no presenta almidón y posee una delgada cutícula que delimita al plasmodio nucelar. El saco embrionario se localiza en el extremo micropilar del plasmodio nucelar, entre los tegumentos interno y externo (Fig. 18). El óvulo es anátropo, bitégmico, tenuinucelado y exóstomo.

\section{DISCUSIÓN}

El crecimiento vegetativo en las podostemaceas se lleva a cabo a diferentes profundidades, dependiendo de la región geográfica y del caudal de los ríos durante la época de lluvia. La antesis en cambio, ocurre en el ambiente aéreo, sólo cuando baja el nivel del agua. En este ciclo de vida, el intervalo de temperatura por lo común es de 14 a $27^{\circ} \mathrm{C}$ y posiblemente el incremento de la temperatura, el decremento del volumen de agua y los 

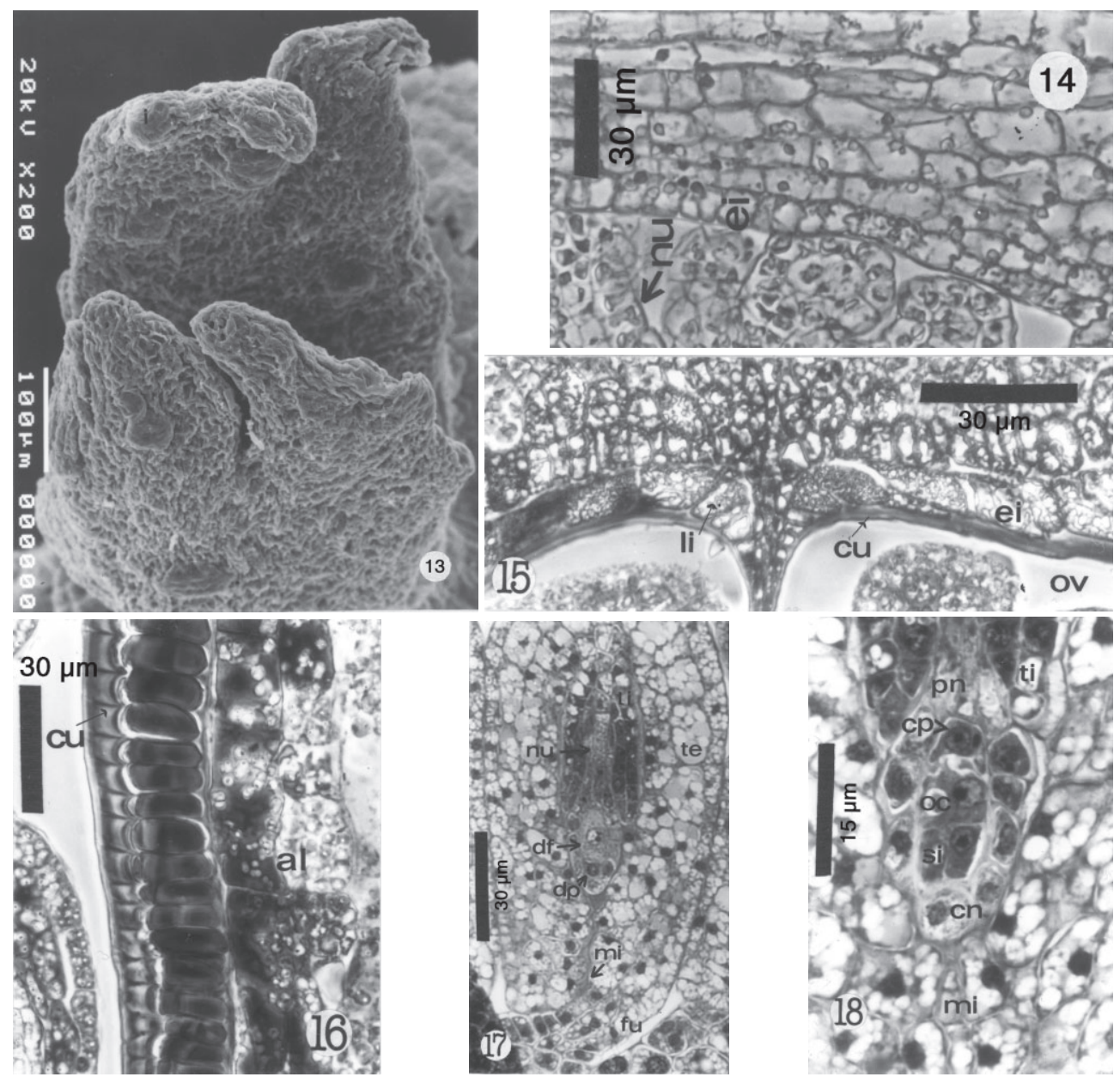

Fig. 13. Estigmas de la etapa (V), vista apical con MEB. Las protuberancias corresponden a los idioblastos (i). Figs. 14-16. Desarrollo de la pared del ovario. Fig. 14. Botón pequeño de la etapa (I). Corte longitudinal mostrando la epidermis interna (ei) y nucelas (nu) en el lóculo del ovario. Fig. 15. Botón grande de la etapa (II) Acumulaciones lipídicas (li) en el citoplasma de la epidermis interna (ei) y depósito inicial de cutícula (cu) sobre las paredes celulares internas. En corte transversal se observan los dos lóculos del ovario (ov). Fig. 16. Botón de la etapa (V). Epidermis interna completamente llena de lípidos y delimitada por una gruesa cutícula. Se observa gran cantidad de almidón (al) en las células parenquimáticas adyacentes. Fig. 17. Botón de la etapa (II). Óvulo anátropo, bitégmico, exóstomo y tenuinucelado, formado por: tegumento externo (te), tegumento interno (ti), funículo (fu) y micrópilo (mi). Se observan la diada funcional (df), la diada picnótica (dp) y el inicio de la degradación de las paredes celulares de la nucela (nu). Fig. 18. Botón de la etapa (II). Saco embrionario monospórico y tetracelular rodeado por células nucelares (cn), entre el tegumento interno (ti) y el micrópilo (mi). Se observan las sinérgidas (si), la ovocélula (oc) y la célula polar (cp). El tegumento interno (ti) delimita al plasmodio nucelar (pn). 
nutrientes disponibles en el vital líquido sean los factores que disparan la diferenciación del meristemo vegetativo a meristemo floral (Sculthorpe, 1967; Sehgal et al., 1993) y tal vez también el alargamiento de los pedicelos (Schnell, 1967).

Acerca de la relación que existe entre la etapa del desarrollo de las flores y la producción de los gametos, con su posición en la planta madre, se observan dos tendencias en la escasa literatura al respecto: en la India, durante la formación del óvulo en Indotristicha ramosissima y Dalzellia zeylanica (Tristichoideae), la célula arquesporial funciona directamente como célula madre de la megaspora y permanece en esta etapa hasta que el nivel del agua disminuye en los ríos donde crecen estas plantas (Arekal y Nagendran, 1977b); en Sudamérica, Weddellina squamulosa (Weddellinoideae) (Engler, 1930; JägerZürn, 1997; Kita y Kato, 2001) presenta células arquesporiales al inicio de la antesis (en el ambiente aéreo) y en ese corto intervalo desarrolla tanto sacos embrionarios como granos de polen (Jäger-Zürn, 1997). En cambio, Apinagia divertens (Podostemoideae) completa el desarrollo de las flores y los gametos dentro del tallo postrado de la planta, mientras ésta se encuentra sumergida (Schnell, 1967). Un caso parecido ocurre con Vanroyenella plumosa (Podostemoideae), que completa la formación de la flor y los gametos cuando se encuentra bajo el agua y el proceso tiene lugar dentro del tallo taloide dorsiventralmente aplanado. En esta especie, al bajar el nivel del agua, rápidamente los pedicelos se alargan y la flor expone anteras y pistilo al ambiente aéreo.

El tipo de desarrollo floral en $A$. divertens y en $V$. plumosa, contrasta con el de $I$. ramosissima, $D$. zeylanica y $W$. squamulosa, pues sugiere que los miembros de la subfamilia Podostemoideae completan el desarrollo de la flor, del óvulo y los granos de polen mientras están sumergidos y este proceso lo desarrollan mucho antes que los miembros de la subfamilia Tristichoideae. A su vez, este hecho contrasta con lo que ocurre en la monogenérica subfamilia Weddellinoideae, donde la gametogénesis se completa al momento de la antesis. La confirmación de lo anterior requiere de estudios en un mayor número de géneros de esta familia, toda vez que, por ejemplo, los botones florales de Polypleurum stylosum (Podostemoideae) surgen bajo el agua, pero completan su desarrollo sólo cuando baja el nivel de la misma y quedan expuestos al ambiente aéreo (Sehgal et al., 1993), lo cual evidencia la necesidad de definir los patrones del desarrollo floral entre las subfamilias de Podostemaceae.

Pared de la antera

Vanroyenella plumosa presenta un desarrollo de la pared de la antera del tipo Básico. Davis (1966) reconoció cuatro tipos: Básico, Dicotiledóneo, Monocotiledóneo y Reducido. Estos tipos son en su mayoría específicos al nivel de familia y Davis (1966) consideró que el desarrollo de la pared de la antera del tipo Básico es el más primitivo y el tipo Reducido es el derivado. Sin embargo, para la gran mayoría de las podostemáceas, la escasa información señala únicamente el número de capas celulares en la pared de la antera madura (Razi, 1949; Chopra y Mukkada, 1966; Kapil, 1970; Jäger-Zürn, 1997) y, aunque limitada, la evidencia disponible sugiere que entre las subfamilias se encuentran diferentes patrones de desarrollo de la pared de la antera aunque, aparentemente, no el de tipo Reducido. Este carácter requiere mayor investigación en la familia Podostemaceae. 
Estigma

A diferencia del gineceo de Weddellina squamulosa, que presenta ovario, estilo y estigma (Jäger-Zürn, 1997), en el de V. plumosa el ovario es conspicuo pero en su ápice no se observa una clara distinción morfológica entre 'estigma' y 'estilo'. Novelo y Philbrick (1993) le Ilaman estilo, o estigma (Novelo y Philbrick, 1997); Rutishauser, et al. (1999) le denominan estigma y consideran que en $V$. plumosa y Marathrum schiedeanum los estigmas pueden (o no) tener un estilo muy corto. En este trabajo se concluye que la estructura receptiva de $V$. plumosa corresponde a un estigma sésil del tipo liso y seco, con cutícula discontinua, en cuyo interior los idioblastos se distribuyen por todo el contorno subepidérmico; por su contenido protéico y de carbohidratos se sugiere una función secretora, seguramente asociada al reconocimiento entre el polen y el estigma y también a la adhesión del grano de polen a la superficie estigmática y su posterior hidratación y germinación. En el parénquima subyacente el tejido de transmisión se extiende hacia la placenta, sin que se conforme la estructura típica de un estilo.

\section{Pared del ovario}

Algunos días después de la antesis, el fruto (cápsula) parece estar maduro pues presenta un color café, con apariencia seca y costillas longitudinales prominentes, pero las semillas contenidas en su interior requerirán algunas semanas más para alcanzar la madurez.

Philbrick y Novelo (1994) señalan que en $V$. plumosa y en algunas otras Podostemaceae de México la maduración de la semilla ocurre durante un período aproximado de tres semanas después de que los tejidos fotosintéticos (hojas, tallos, y raíces) se han desprendido, desaparecido o secado. Así, las reservas necesarias para el desarrollo de las semillas no provienen directamente de los tejidos fotosintéticos parentales, sino que aparentemente proceden de los lípidos y el almidón almacenados en grandes cantidades en la pared del ovario y en la placenta. Hasta donde se sabe, esto no ha sido observado en ninguna otra familia de angiospermas.

\section{Óvulo y saco embrionario}

El desarrollo del saco embrionario en $V$. plumosa es del tipo Apinagia y comparte este carácter con la mayoría de las especies de la familia. El plasmodio nucelar en esta especie se forma antes de la fertilización, como ocurre con otras especies de la subfamilia Podostemoideae. El hecho de que en especies de la subfamilia Tristichoideae el plasmodio nucelar se forma después de la fertilización y que en la monogenérica subfamilia Weddellinoideae la formación del plasmodio nucelar parece estar algo intermedia (JägerZürn, 1997: 175), plantea la necesidad de mayor investigación al respecto, pues el tiempo de formación del plasmodio nucelar parece ser un carácter variable dentro de la familia Podostemaceae. 
Murguía et al.: Desarrollo de los Vertículos Sexuales de Vanroyenella plumosa (Podostemaceae)

\section{CONCLUSIONES}

La mejor manera de clarificar los patrones de desarrollo embriológico y los sistemas de reproducción en la familia Podostemaceae requiere de un enfoque holístico que incluya la relación del proceso embriológico, con el desarrollo de estas plantas en su ambiente natural. Asimismo, se requieren más estudios embriológicos que sean un apoyo para la delimitación taxonómica en la familia Podostemaceae, especialmente en diferentes especies que habitan regiones del mundo aún no estudiadas, como el continente africano y otras regiones sudamericanas en las que se encuentran muchos géneros endémicos. Ahora estamos ampliando el estudio de otros géneros de podostemáceas en México y Sudamérica con el objeto de contribuir al conocimiento biológico de este grupo.

\section{AGRADECIMIENTOS}

Los autores agradecen el apoyo de la Dirección General de Asuntos del Personal Académico (PAPIIT, IN-212596), Universidad Nacional Autónoma de México; el trabajo de campo del M. en C. Ricardo Wong y de la M. en C. Norma Oropeza Hernández (quien es autora de la figura 10) y el trabajo de microfotografía de la Biól. Ana I. Bieler Antolín, el Biól. Alfredo Gamboa Romero y M. en C. Alejandro Martínez Mena, del Laboratorio de Microcine, Facultad de Ciencias-UNAM. Agradecemos a la Dra. Paula Rudall (Kew Herbarium) la revisión e invaluables comentarios a la primera versión de este manuscrito y a la Dra. Sonia Vázquez Santana y a la M. en C. R. Margarita Ponce Salazar la lectura de la versión final de este trabajo.

\section{LITERATURA CITADA}

Arekal, G. D. y C. R. Nagendran. 1977. The female gametophyte in two Indian genera of Tristichoideae (Podostemaceae) - A reinvestigation. Proc. Indian Acad. Sci. 86: 287-294.

Battaglia, E. 1987. Embryological questions: 11. Has the debated case of Podostemaceae been resolved? Annali di Botanica 45: 37-64.

Chopra, R. N. y A. J. Mukkada, 1966. Gametogenesis and pseudo-embryo sac in Indotristicha ramosissima (Wight) van Royen. Phytomorphology 16: 182-188.

Cook, C. D. K. 1996. Aquatic plant book. 2a. ed. Amsterdam, Nueva York: SPB Academic Publishing. ....pp.

Cronquist, A. 1981. An integrated system of classification of flowering plants. Columbia University Press. Nueva York. 1262 pp.

Davis, G.L. 1966. Systematic embryology of the angiosperms. John Wiley \& Sons, Inc. Nueva York. $528 \mathrm{pp}$.

Engler, A. 1930. Reihe Podostemonales. In: Die natürlichen Pflanzenfamilien. 2a. ed. Engelmann. Leipzig. Vol. 18a: 1-68, 483-484.

Graham, S. A. y C. E. Wood, Jr. 1975. The Podostemaceae in the southeastern United States. J. Arnold Arb. 56: 456-465.

Jäger-Zürn, I. 1997. Embryological and floral studies in Weddellina squamulosa Tul. (Podostemaceae, Tristichoideae). Aquat. Bot. 57: 151-182.

Jäger-Zürn, I. 2000. Podostemaceae depend on sticky biofilms with respect to attachment to rocks in waterfalls. Int. J. Plant Sci. 161(4): 599-607. 
Johansen, D. A. 1940. Plant microtechnique. McGraw-Hill Book Co. Inc. Londres. 523 pp.

Kapil, R. N. 1970. Podostemaceae. Bull. Ind. Natl. Sci. Akad. 41: 104-109.

Kita, Y. y M. Kato. 2001. Infrafamilial phylogeny of the aquatic angiosperm Podostemaceae inferred from the nucleotide sequences of the matK gene. Plant Biol. 3: 156-163.

Nagendran, C. R. 1974. Is the embryo-sac of Podostemaceae bisporic? Current Sci. 43: 259-260.

Novelo R., A. y C. T. Philbrick. 1993. Vanroyenella: A new genus of Podostemaceae from Jalisco, Mexico. Syst. Bot. 18: 64-67.

Novelo R., A. y C. T. Philbrick. 1997. Taxonomy of Mexican Podostemaceae. Aquat. Bot. 57: 275-303.

O'Neill, S. P., J. M. Osborn, C. T. Philbrick y A. Novelo. 1997. Comparative pollen morphology of five New World genera of Podostemaceae. Aquat. Bot. 57(1-4): 133-150.

Philbrick, C. T. 1984. Aspects of floral biology, breeding system, and seed and seedling biology in Podostemum ceratophyllum (Podostemaceae). Syst. Bot. 9(2): 166-174.

Philbrick, C. T. y A. Novelo R. 1993. River-weeds: A fascinating family of aquatic flowering plants. Aquaphyte 13(1): 1-6.

Philbrick, C. T. y A. Novelo. R. 1994. Seed germination of Mexican Podostemaceae. Aquat. Bot. 48: 145-151.

Philbrick, C. T. y A. Novelo R. 1995. New world Podostemaceae: Ecological and evolutionary enigmas. Brittonia 47: 210-222.

Philbrick, C. T. y A. Novelo R. 1998. Flowering phenology, pollen flow, and seed production in Marathrum rubrum (Podostemaceae). Aquat. Bot. 62: 199-206.

Razi, B. A. 1949. Embryological studies of two members of the Podostemaceae. Bot. Gaz. 3: 211-218.

Rutishauser, R. 1997. Structural and developmental diversity in Podostemaceae (river weeds). Aquat. Bot. 57 : 29-70.

Rutishauser, R., A. Novelo R. y C. T. Philbrick. 1999. Developmental morphology of New World Podostemaceae: Marathrum and Vanroyenella. Int. J. Plant Sci. 160: 29-45.

Sehgal, A., H. Y. Mohan Ram y J. R. Bhatt. 1993. In vitro germination, growth, morphogenesis and flowering of an aquatic angiosperm, Polypleurum stylosum (Podostemaceae). Aquat. Bot. 45: 269-283.

Sculthorpe, C. D. 1967. The biology of aquatic vascular plants. St. Martin's Press. Nueva York. 610 pp.

Schnell, R. A. A. 1967. Études sur l'anatomie et la morphologie des Podostémacées. Candollea 22(2): 157-225.

Van Royen, P. 1953. The Podostemaceae of the New World II. Acta Bot. Neerl. 2: 1-20.

Van Steenis, C. G. G. J. 1981. Rheophytes of the world. Sijthoff and Noordhoff. Alphen aan den Rijn. The Neederlands. 408 pp. 